\title{
Establishment and Fractionation of Metastatic Axillary Lymph Node Cell Suspension for Determination of Protein Expression Levels of Nuclear cFOS and Cytosolic TGF $\beta 1$ from Breast Cancer Patients
}

Vesna Ivanović ( $\square$ vesnai@eunet.rs )

VINCA Institute of Nuclear Sciences: Univerzitet u Beogradu Institut za nuklearne nauke Vinca https://orcid.org/0000-0002-3760-1032

Nasta Dedović-Tanić

VINCA Institute of Nuclear Sciences: Univerzitet u Beogradu Institut za nuklearne nauke Vinca

Zorka Milovanović

Institute of Oncology and Radiology of Serbia: Institut za onkologiju i radiologiju Srbije

Bratislav Stojiljković

Oncology Institute of Southern Switzerland: Istituto Oncologico della Svizzera Italiana

Miroslav Demajo

VINCA Institute of Nuclear Sciences: Univerzitet u Beogradu Institut za nuklearne nauke Vinca

Vesna Mandušić

VINCA Institute of Nuclear Sciences: Univerzitet u Beogradu Institut za nuklearne nauke Vinca

\section{Methodology}

Keywords: axillary lymph nodes, cFOS, TGF $\beta 1$, FNCS, Fractionated Nodal Cell Suspension

Posted Date: October 29th, 2021

DOI: https://doi.org/10.21203/rs.3.rs-1004502/v1

License: (c) (i) This work is licensed under a Creative Commons Attribution 4.0 International License.

Read Full License 


\section{Abstract \\ Background.}

Metastatic Axillary Lymph Node (mALN) status is currently the most important prognostic factor in the management of primary breast cancer (BC). Thus, development of specimens which enable identification of new mALN markers, involved in the progression of the disease, are of considerable interest. The specific aim of this work was to describe the method of establishment of Metastatic Axillary Nodal Cell Suspension and its fractionation, termed Fractionated Nodal Cell Suspension (FNCS), into nuclear and cytosolic extracts to enable determination of protein expression levels of nuclear cFOS and cytosolic Transforming Growth Factor $\beta 1$ (TGF $\beta 1$ ) in BC patients.

\section{Results.}

To standardize the procedure, HeLa cells were successfully fractionated into nuclear/cytosolic extracts with confirmed presence of nuclear cFOS and cytosolic TGF $\beta 1$ proteins. Subsequently, the ALN Cell Suspension specimens were obtained and further fractionated from a pilot sample of six ALN tissue pairs, mALN versus autologous normal ALN (nALN), dissected from invasive BC patients. The mALN results revealed statistically significant overexpression in nuclear cFOS and cytosolic TGF $\beta 1$ protein levels, which was proportional to the respective values of mALN diameter of tumor deposits.

\section{Conclusions.}

Detailed protocol for establishment and fractionation of mALN cell suspension specimens, termed FNCS, into nuclear and cytosolic extracts is here described for the first time. This approach might be a convenient ex vivo model for simultaneous analysis of protein, RNA and DNA biomarkers from nuclear/cytosolic extracts of the same mALN tissue sample. It might have potential to enable, in the age of genomics and personalized medicine, an identification of novel mALN biomarkers and thus improve the screening, diagnosis and prognosis of invasive BC.

\section{Background}

Breast cancer (BC) is a leading malignancy in women worldwide (1) with extremely heterogeneous cell morphology $(2,3)$ including more than 20 distinct subtypes that differ genetically and clinically(4). Distant metastasis is the main cause of death in BC patients. Axillary lymph nodes (ALN) are the main doorway for tumor cell escape from the primary site to other regions of the body (5). Consequently, metastatic ALN (mALN) are considered the most important prognostic factors and powerful source of biomolecules that may become reliable metastatic biomarkers. In spite of that, very few studies have been conducted to identify BC biomarkers associated with the ALN metastasis of BC. Therefore, inclusion 
of new mALN molecular biomarker profiles has been proposed to predict nodal status at the time of BC diagnosis (6).

Considerable research attention has been focused on a role of deregulation of Transforming Growth Factor $\beta 1$ (TGF 31 ) as tumor promoter step favoring BC invasion and metastasis(7). Moreover, accumulating evidence shows that FOS transcription factor binding motifs are critical for the regulation of TGF $\beta 1$ expression (8). Thus, cFOS elevation may have utility as a complementary candidate biomarker of $B C$ invasiveness, co-expressed with TGF $\beta 1$. Consequently, we have, previously proposed that cFOS and TGF $\beta 1$ proteins may be considered as a pair of biomarkers of an early assessment of invasive $B C(7,8)$, providing adequate invasive $\mathrm{BC}$ specimens are available. In the past, primary tumor tissue had been fractionated into nuclear $(9)$ or cytosolic $(10,11)$ extract to assess specific biomarkers of interest. Until recently, however, the protocol for fractionation of mALN nuclear and cytosolic extracts has not been available, presumably due to the specific tough, fibrous nature of mALN tissue.

To date, diameter of tumor deposits and proliferation index $\operatorname{Ki} 67(6,12,13)$ are the most prominent clinically used features of mALN. Both parameters are detected by routine histology(14) involving the tissue paraffin blocks of $4-\mu \mathrm{m}$ slices for each node $(15,16)$ and their staining with either Haematoxylin and Eosin (H\&E) or Immunohistochemistry (IHC), respectively(17). Although indispensable, the histology methodology imposes some limitations(16). Namely, in a significant portion of cases, due to clustered spacial distribution of tumor cells within a lymph node, the histology sectioning generates sampling errors leading to false negative mALN sections(18). Consequently, the pool of biomarkers in various slices may be different. To overcome this problem, Edwards and co-workers(19) introduced mALN Cell Suspension as new specimens thereby covering the whole content of entire mALN. Based on this mALN specimen source, we developed the method, termed Fractionation of Nodal Cell Suspension (FNCS), which includes the mALN Cell Suspension approach and its fractionation into nuclear and cytosolic extracts to be suitable for determination of protein expression levels of respective native proteins. Using this experimental design, we have previously observed overexpression of TGF $\beta 1$ protein in cytosolic extracts of mALN(7). Likewise, we encountered a case of an advanced Triple Negative Breast Cancer (TNBC) patient with overexpressed both cytosolic TGF $\beta 1$ and nuclear cFOS proteins as a pair of mALN biomarkers for an early assessment of TNBC poor prognosis(8). However, in above mentioned studies(7, 8), apart from the outlined methods used, specific experimental protocols were not described. Having in mind that the FNCS design might help to generate an important predictive tool suitable for comparative analysis of individual patients in present era of genomics and personalized medicine(2), we undertook the present study. The main goal was to describe the full methodology of establishment and fractionation of mALN Cell Suspension thus providing FNCS specimens of nuclear and cytosolic extracts and determination of protein expression levels of respective cFOS and TGF $\beta 1$.

The workflow of the this study is presented in Figure 1. The following steps, included in the experimental design, were: $i$ ) mechanical disaggregation of mALN, chopped and filtered through $100 \mu \mathrm{m}$ sieve devices, to obtain mALN cell suspension free from fat and connective tissue (mALN Cell 
Suspension); ii) model protocol of HeLa cell fractionation into nuclear and cytosolic extracts to be implemented on mALN Cell Suspension to obtain FNCS specimens and generate nuclear/cytosolic extracts; iii) determination of protein expression level of nuclear cFOS and cytosolic TGF $\beta 1$ by ELISA; iv) correlation of the respective cFOS and TGF $\beta 1$ biomarker levels with mALN diameter of tumor deposits for each BC patient.

Since mALN tissue sample is heterogeneous in terms of its cell content (including: various BC malignant clones, fibroblasts, macrophages, lymphocytes etc.) this protocol enables the use of autologous normal ALN (nALN) of each patient as an optimal choice of negative control. Taken together, this study provides tools to researchers termed FNCS, in which mALN and nALN tissue samples are used as initial ex vivo materials, to follow the protocol "from tough mALN/nALN tissue, through mALN/nALN Cell Suspension, to fractionationate the nuclear/cytosolic extracts" and enable ELISA determination of respective protein biomolecules. The method provides considerable advantages, when compared to current pathohistological BC diagnostics which is, during routine examination, rather limited to defined slices which cannot cover the complete volume of the nodal tissue.

\section{Results}

I Hela cell in vitro model for fractionation of nuclear and cytosolic extracts and determination of respective protein expression levels of cFOS and TGF $\beta 1$

In order to save the precious ALN tissue, the experimental approach included the use of HeLa cell culture to confirm the fractionation protocol described in Methods. The time courses of serum-induced nuclear cFOS and cytosolic TGF $\beta 1$ proteins are presented in Figure 2.

The data reveal that nuclear cFOS reached and kept the plateau values between 4-6 hours after serum treatment (Figure 2A). Accordingly, as recommended by the manufacturer (Chemicon International), the 4 hr nuclear extract point was used as cFOS positive control sample in subsequent ALN measurements of cFOS. To verify the usefulness of the selected fractionation protocol on cytosolic TGF- $\beta 1$ detectability, autologous time points of HeLa cytosolic extracts were analyzed by TGF- $\beta 1$ ELISA. The results in Figure $2 \mathrm{~B}$ illustrate that the cytosolic TGF- $\beta 1$ was induced rapidly and reached maximal value at 2 hours after serum treatment, followed by continuous decrease in values. As expected, neither was cFOS detectable in cytosolic extracts, nor was TGF- $\beta 1$ detectable in nuclear extracts of HeLa cells (data not shown). Taken together, these results indicate that the selected fractionation protocol has successfully separated cytosolic from nuclear fraction and preserved the native nature of the analyzed proteins.

\section{Description of ALN tissue morphology}

These findings encouraged us to morphologically characterize mALN tissue of pilot samples of six patients with clinical characteristics of invasive BC. These patients, labeled 1-6, are described in Table 1. In addition, respective normal ALN (nALN) tissue was selected from each patient as 
Table 1

Clinical and pathohistological characteristics of BC patients from whom metastatic ALNs were dissected Characteristics Patients' number

\begin{tabular}{|c|c|c|c|c|c|c|}
\hline & 1 & 2 & 3 & 4 & 5 & 6 \\
\hline Age at surgery & 74 & 39 & 70 & 52 & 48 & 66 \\
\hline $\begin{array}{l}\text { Menopausal } \\
\text { status }\end{array}$ & Post & Pre & Post & Post & Pre & Post \\
\hline $\mathrm{ER}^{+}$ & 0 & 0 & 8 & 8 & 7 & 8 \\
\hline PR & 0 & 0 & 7 & 0 & 0 & 8 \\
\hline HER2 & 0 & 0 & $1+$ & 0 & $1+$ & $1+$ \\
\hline TNBC status & TNBC & TNBC & nonTNBC & nonTNBC & nonTNBC & nonTNBC \\
\hline $\begin{array}{l}\text { Histological } \\
\text { Grade }^{++}\end{array}$ & III & $\|$ & II & II & II & II \\
\hline Type AJCC ${ }^{+++}$ & ILC/ IAC & IDC & ILC & ILC & ILC & ILC \\
\hline Clinical Stage & IIIB & IIIA & IIIA & IIIA & II & II \\
\hline $\begin{array}{l}\text { Lymph node } \\
\text { status }\end{array}$ & $3 * / 8$ & 4/18, pni+ & $\begin{array}{l}7 / 13 \\
\text { pni+*** }\end{array}$ & $7 / 14$ & 1/8, pni+ & $1 / 15$ \\
\hline \multirow[t]{2}{*}{ pTNM } & \multirow[t]{2}{*}{$\begin{array}{l}\text { pT4d**, } \\
\text { N2,Mo }\end{array}$} & \multirow[t]{2}{*}{$\begin{array}{l}\text { pT1a, } \\
\text { N2a, Mo }\end{array}$} & \multirow[t]{2}{*}{$\begin{array}{l}\text { pT2, N2a, } \\
\text { Mo }\end{array}$} & $\begin{array}{l}\text { pT: } \\
\text { pTU1n: 2, } \\
\text { N2a, Mo }\end{array}$ & \multirow[t]{2}{*}{$\begin{array}{l}\text { pT1c, N1a, } \\
\text { Mo }\end{array}$} & \multirow[t]{2}{*}{$\begin{array}{l}\text { pT1c, N1a, } \\
\text { Mo }\end{array}$} \\
\hline & & & & pTU2n: 1c & & \\
\hline
\end{tabular}

an optimal choice of negative control tissue. Subsequent H\&E staining was performed on pairs of surgical tissue for each patient. Figure 3 illustrates cell morphology of ALN tissue pairs for patient \#1 in Table 1. The results for control nALN, reveal stasis, multifocal lipomatosis

lipomatosis and sinus histiocytosis of the lymph node without metastatic deposits (Figure 3A). On the other hand, in case of mALN (Figure 3B) the data show the morphology which reveals large, polygonal cells, eosinophilic cytoplasm and hyperchromatic nuclei, conspicuous anisocytosis that are, by their cytomorphological features, identical to primary breast cancer.

III Individualized comparative analysis of diameter of tumor deposits versus respective ALN nuclear cFOS and cytosolic TGF- $\beta 1$ levels. 
The individualized diameter of tumor deposits (range: 80-1.8 mm, mean value: $23.9 \mathrm{~mm}$ ) assessed from the H\&E staining of formalin-fixed, paraffin-embedded slices, are presented in and Figure 4A and Table 2.

Table 2

Individual parameter values measured in the selected single metastatic ALN (mALN) for each of the BC patient presented in Table 1 and described in Methods and Figure 4.

\begin{tabular}{|c|c|c|c|c|c|c|}
\hline \multirow[t]{2}{*}{ Parameter } & \multicolumn{6}{|c|}{ Patients' number } \\
\hline & 1 & 2 & 3 & 4 & 5 & 6 \\
\hline Diameter of tumor deposits* $(\mathrm{mm})$ & $80.0 * *$ & 9.5 & 14.5 & 13.5 & 1.8 & n.a.+ \\
\hline$\%$ of malignant cells & $80 \%$ & $100 \%$ & $100 \%$ & $100 \%$ & $30 \%$ & n.a. \\
\hline Presence of micrometastasis*** & none & none & none & none & positive & n.a. \\
\hline Initial tissue weight $^{++}(\mathrm{mg})$ & 79 & 72 & 19 & 66 & 63 & 53 \\
\hline Total viable cell number $\left(\times 10^{-6}\right)$ & 18.6 & 3.6 & 5.2 & 9.0 & 3.8 & 3.9 \\
\hline Nuclear protein yield (mg) & 3.2 & 0.6 & 1.0 & 1.7 & 1.1 & 0.8 \\
\hline Cytosolic protein yield (mg) & 6.5 & 1.2 & 1.7 & 2.5 & 0.9 & 1.2 \\
\hline cFOS level (\%) & 15.50 & 8.75 & 13.20 & 0.00 & 0.00 & 0.00 \\
\hline TGF $\beta 1$ level (ng/mg protein) & 3.60 & 1.20 & 0.90 & 1.02 & 0.67 & 1.08 \\
\hline \multicolumn{7}{|c|}{$\begin{array}{l}\text { *: The size of tumor deposits was assessed from the H\&E slices of formalin-fixed, paraffin-embeddec } \\
\text { ALN tissue; }\end{array}$} \\
\hline \multicolumn{7}{|c|}{$\begin{array}{l}\star \star \text { : "mALN1" essentially exhibited the conglomerate size: } 80 \text { × } 50 \text { × } 40 \mathrm{~mm} \text {, with malignant infiltration } \\
\text { of surrounding ALN }\end{array}$} \\
\hline \multicolumn{7}{|l|}{ tissue; } \\
\hline \multicolumn{7}{|l|}{$\star \star \star$ : observed morphologically; } \\
\hline $\begin{array}{l}\text { +: not available due to much too sm } \\
\text { TGF } \beta 1 \text { analysis. }\end{array}$ & N size & he $\epsilon$ & $\mathrm{mAL}$ & was & for cFC & \\
\hline
\end{tabular}

However, H\&E staining does not always provide enough contrast to differentiate all tissues and cellular structures (21), therefore in these cases more specific stains by IHC method are used. Likewise, quantifying the IHC stains is also limited, subject to human error, and not standardized worldwide (22). Due to these disadvantages, the protocol of FNCS method was implemented on pairs of ALN tissues from patients 1-6 in Table 1 as described in Methods. The quantitative parameters obtained from these experimental procedures are summarized in Table 2. 
For each patient labeled consecutively 1-6, they include: the initial tissue weight (range: 79-19 mg), total viable cell number (range: 18.6-3.6 $\times 10^{-6}$ ), yields of total nuclear protein (range: $3.2-0.6 \mathrm{mg}$ ) and total cytosolic protein ( range: $6.5-0.9 \mathrm{mg}$ ) of the metastatic ALN. Respective measurements of normal ALN values of the same parameters revealed a similar ranges and yields as described in Table 2. (data not shown).

To exact levels of cFOS and TGF $\beta 1$ expression in the nALN/mALN tissue pairs of respective FNCS specimens are presented in Figures 4B \&4C. The data in Fig. 4B indicate that cFOS levels in mALN nuclear extracts (mean value $12.47 \%$, range: $15.5-8.71 \%, n=3)$ were significantly $(p<0.05)$ elevated when compared with those of $n A L N$ (mean value: $4.84 \%$, range: $12.1-0.34 \%, n=6)$. Whereas, the data in Figure 4C show that TGF $\beta 1$ levels in mALN cytoplasmic extracts (mean value: $1.41 \mathrm{ng} / \mathrm{mg}$ protein, range: 3.6$0.67 \mathrm{ng} / \mathrm{mg}$ protein, $\mathrm{n}=6)$ were significantly $(\mathrm{p}<0.01)$ elevated when compared with those of $\mathrm{nALN}$ tissue (median value: $0.55 \mathrm{ng} / \mathrm{mg}$ protein, range: $0.90-0.29 \mathrm{ng} / \mathrm{mg}$ protein, $\mathrm{n}=6$ ). Taken together, the results in Figure 4 reveal a statistically significant overexpression of respective nuclear cFOS and cytosolic TGF $\beta 1$ proteins in mALN which was proportional to the size of respective mALN tumor deposits (Table 2). As a consequence, they suggest that CFOS and TGF $\beta 1$ overexpression is associated with the presence of metastatic cells in the ALN-positive tissue specimens. Moreover, Figure 4 illustrates complementary role of routine histology and FNCS analysis in confirmation of an individual putative metastatic biomarker, suggesting that both methods are beneficial in diagnostics of invasive $\mathrm{BC}$ patients.

\section{Discussion}

It is now well established that accurate staging of the ALN for metastatic disease is critical in deciding the appropriate management of BC patients. Metastasis to the axillary nodes is the earliest sign of the BC metastatic spread and this process occurs at a higher rate than any single distant organ metastasis (23). However, probability of false negatives due to the routine ALN histology sectioning underestimates ALN positivity in a significant proportion of cases (for details see Introduction). Likewise, pathologists face difficulties in detecting ALN micrometastasis. In these cases they use IHC plus multiple sectioning of each node (up to 20 slides per node) or serial sectioning in various designs. Both sectioning procedures are extremely time consuming and expensive (19). With these justifications, in the present study we described in details the establishment and fractionation protocol of mALN cell suspension into nuclear and cytosolic extract, termed Fractionated Nodal Cell Suspension (FNCS) as bench flow procedure to investigate invasive BC biomarkers and possibly assess the ALN status as the subsidiary tool in routine clinical use.

Currently, available model systems for pre-clinical metastatic BC research, include primary cell culture, immortalized cell lines, mouse xenographts $(24)$ and organoid technology $(25,26)$. Although essential for discovery, development and testing of new therapies, these models have both advantages and disadvantages(17). In spite of that, very few studies have been conducted to identify BC biomarkers associated with the ALN metastasis of BC. Among these, by using absolute quantitative real-time reverse transcription-PCR (qRT-PCR), mammaglobin has been identified with high sensitivity and specificity in BC 
for the detection of metastatic ALN (27). Therefore, inclusion of additional new mALN molecular biomarker profiles is needed to predict nodal status at the time of BC diagnosis (6).

Here we describe the design of a potentially new specimen, termed Fractionated Nodal Cell Suspension to establish and fractionate mALN Cell Suspension based on disaggregation of dissected BC mALN tumor tissue, preparation of mALN Cell Suspension, its further fractionation and determination of protein expression level of nuclear CFOS and cytosolic TGF $\beta 1$ from the same ALN sample.Our results reveal $a$ significant overexpression in respective nuclear cFOS and cytosolic TGF $\beta 1$ proteins, which was proportional to the size of respective mALN tumor deposits.Major limitation of this data pertains to the small sample size. Nevertheless, our findings imply that the cFOS and TGF $\beta 1$ overexpression is associated with the presence of metastatic BC cells. Large scale studies, however, are necessary to confirm the conclusion.

Taken together, the FNCS method may facilitate simultaneous comparative analysis of other protein, RNA and DNA biomarkers from the same ALN tissue sample. This might provide very powerful measurements which allow direct genotypic and phenotyping correlations (23). Alternatively, we expect advanced application of the FNCS model system which might include an enrichment of a particular malignant clone content starting with mALN Cell Suspension specimen and clonal evolution during the migration e.i. metastasis. Namely, mALN Cell Suspension specimens being heterogeneous in the cell population (for details see Introduction) could be further separated by selective gradient to obtain individual cell types(17) to be further sorted out(28) by Fluorescence Activated Cell Sorter (FACS). After these steps, samples of homogeneous tumor cell clones are to be obtained. The proposed FNCS design might be advantageous, when compared to highly sophisticated and expensive Laser Capture Microdissection (LCM) which is based on the small number of cells consequently yielding low RNA and DNA amounts. Furthermore, described FNCS design provides an excellent sample source for investigating of molecular changes during the disease progression.

\section{Conclusion}

Our study provides, for the first time, detailed description of the experimental method for establishment and fractionation of Metastatic Axillary Nodal Cell Suspension into nuclear and cytosolic extracts, termed FNCS, for determination of protein expression levels of respective cFOS and TGF $\beta 1$. This convenient procedure might be a valuable tool in pre-clinical research of other invasive BC biomarkers. It has considerable advantages, when compared to pathohistological ALN diagnostics, since one need not worry about false negatives and one can reliably quantify treatment-dependent comparative biomarker levels of individual patients. Thus, in the present era of genomics and personalized medicine, the described FNCS method might facilitate the identification of new mALN biomarkers and improve the screening, diagnosis and prognosis of invasive BC.

\section{Methods}




\section{Patients' tissue}

Post-operative ALN tissue was dissected from 12 consecutive female BC patients attending the hospitals within six weeks (from August 24, to October 04, 2007), screened histopathologically to obtain the study cohort of six ALN-positive patients described in Table 1. None of these patients were previously treated. The proposed investigation had received the Institutional Review Board approval and a written informed consent was obtained from each woman according to the National Health Regulation. For each BC patient, a fresh tissue of single metastatic ALN with maximal size of tumor deposits was divided in half. The first half underwent routine histopathological examination using cryotome-cut frozen sections stained by H\&E. After confirmation of the presence of metastatic deposits, the second half of fresh tissue - selected for this research was immediately snap-frozen and stored at $-70^{\circ} \mathrm{C}$, within the shelf time of 2 months. Simultaneously with mALN, autologous, histopathologically verified, normal ALN control (nALN) was collected. These pairs of tissue samples, after defrosting, were subjected to disaggregation protocol (see below) to establish respective ALN Cell Suspensions and further fractionation to obtain FNCS specimens for subsequent cFOS and TGF $\beta 1$ determination.

\section{Protocol for disaggregation of mALN tissue and establishment of mALN Cell Suspension specimen}

Previous mechanical disaggregation procedures of ALN tissue involved chopping with scalpel blade and multiple injections (19), use of rotating knifes (15) and filtering through $100 \mu \mathrm{m}$ cell strainer (16). In our study, frozen ALN tissue specimens were processed for fractionation on ice in the following manner:

a. The ALN tissue samples were quickly thawed, the weight measured and then chopped with scalpel in a small petri dish; $\mathbf{b}$. The pieces of ALN tissue were resuspended with PBS $(4 \times 1 \mathrm{~mL})$ and simultaneously transferred on an INOX 18/10 sieve (mesh size 100x100 $\mu \mathrm{m}$, net diameter $\varnothing 20 \mathrm{~mm}$ ) obtained from Fasil A.D. Arilje, Serbia, www.fasil.co.rs) which is placed above a new petri dish (Figure 5); c. Macerated tissue was pulverized on the sieve surface with rubber piston

to separate fat and connective tissue from intact cells which are filtered through a mesh into a petri dish; d. The cell suspension was then transferred into an Ependorf tube, centrifuged $\left(850 \mathrm{~g}, 15 \mathrm{~min}, 4^{\circ} \mathrm{C}\right)$, and the cell pellet packed volume $\left(\mathrm{V}_{\text {pack }}\right)$ estimated; e. The supernatant was decanted and the obtained cell pellet diluted with $5 \times \mathrm{V}_{\text {pack }}$ of ice-cold hypotonic lysis buffer; f. An aliquot (50 $\left.\mu \mathrm{L}\right)$ of diluted cell pellet was taken for viable cell counting with heamocytometer (Noybower chamber) by Trypan blue exclusion.

Further steps of fractionation of mALN cell suspension (1-10) were identical as performed for HeLa cells (see below).

\section{Hela cells}


HeLa cells were grown in RPMI 1640 medium supplemented with 10\% Fetal Calf Serum (serum) in the CO2 incubator. For the time course experiment, 6 medium T flasks (dimensions: $75 \mathrm{~cm}^{2}$ ) were grown until $80-90 \%$ confluency. Then cell monolayers, in all flasks, were washed with PBS followed by addition of serum free RPMI which was left to incubate with the cells for 12 hour. At the time point "zero", a moment after a 12-hour incubation ended, serum free RPMI was replaced by the working medium (RPMI plus 10\% FCS) to initiate serum-treatment. Cell suspension from the "zero" flask was fractionated immediately and successive fractionations followed at time points of 2, 4, 5, 6 and 7 hours.

\section{Protocol for fractionation of HeLa cells and/or mALN Cell Suspension}

Fractionation into nuclear and cytosolic extracts of HeLa cells and/or mALN Cell Suspension was prepared by the modifications of the protocols of Prusty et al (9) and Riol et al (29). Considering the facts that the quoted references were used on primary tumor tissue and lymphocytes, respectively, we here describe the full fractionation protocol used in this study:

1.After trypinization of the HeLa cell monolayer and determination of the cell pellet packed volume $\left(\mathrm{V}_{\text {pack }}\right)$, the cell pellet was resuspended in $5 x \mathrm{~V}_{\text {pack }}$ of ice-cold hypotonic lyses buffer (see below under Extraction Solutions); 2.Lysate was incubated on ice for $15 \mathrm{~min}$, centrifuged at $850 \mathrm{~g}$ for $15 \mathrm{~min}$ at $4^{\circ} \mathrm{C}$, and supernatant discarded; 3 . Cell pellet was resuspended in $2 \mathrm{xV}_{\text {pack }}$ of ice-cold hypotonic lyses buffer, and homogenized by drawing and ejecting the cell suspension content with a syringe/No 27 gauge needle; 4. Homogenate was centrifuged at $8.000 \mathrm{~g}$ for $20 \mathrm{~min}$ at $4^{\circ} \mathrm{C}$, and supernatant saved (containing cytosolic extract) and an aliquot $(50 \mu \mathrm{L})$ was used for total cytosolic protein determination; 5 . Remaining cytosolic extract was immediately aliquoted, snap frozen with liquid nitrogen and stored at $-70^{\circ} \mathrm{C}$ for TGF $\beta 1$ ELISA analysis, within the shelf time of 4 months; 6 . Remaining pellet (which contains the nuclear

portion of the cell lysate) was resuspended on ice in $1 \times V_{\text {pack }}$ (the original cell pellet volume) in the extraction buffer (see below, under Extraction Solutions); 7. Nuclei were lysed (disrupted) by drawing and ejecting the content with a syringe/No 27 gauge needle, with addition of 1\% Igepal CA-630 when necessary; 8. Homogenate was gently agitated for $30 \mathrm{~min}$ on ice and centrifuged at $18.000 \mathrm{~g}$ for $10 \mathrm{~min}$ at $4^{\circ} \mathrm{C}$; 9 . Supernatant (which contains nuclear extract) was saved, an aliquot taken for total nuclear protein determination; 10 Remaining nuclear extract was immeditelly aliquoted, snap frozen with liquid nitrogen and stored at $-70^{\circ} \mathrm{C}$ for cFOS determination.

\section{Solutions and reagents}

Fractionation of both HeLa cells and ALN cell suspensions included the following buffers: A. Hypotonic cell lysis buffer: 10 mM HEPES pH 7.9, $1.5 \mathrm{mM} \mathrm{MgCl}_{2}, 10 \mathrm{mM} \mathrm{KCl,} 2.5$ mM DTT, 0.1\% Triton X-100, plus PKIC (Protein Kinase Inhibitor Cocktail); and B. Nuclear extraction buffer: 20 mM HEPES pH 7.9, 1.5 mM $\mathrm{MgCl}_{2}, 420$ mMNaCl, 0.2 mM EDTA, 2.5 mM DTT, 1\% Igepal CA-630, 25\% (v/v) glycerol plus PKIC. In order to reduce proteolysis, dephosphorylation and denaturation of proteins, related inhibitors were added into the lysing buffers prepared as stock solutions of inhibitor cocktails: I. 50 x PIC (Protease Inhibitor Cocktail) in ethanol as solvent containing: $0.5 \mathrm{mg} / \mathrm{mL}$ leupeptin; $0.5 \mathrm{mg} / \mathrm{mL}$ pepstatin; $0.8 \mathrm{mg} / \mathrm{mL}$ 
benzamidine hydrochloride hydrate; and 0.1 M PMSF. The stock was aliquoted in $50 \mu \mathrm{L}$ aliquots and kept at $-20^{\circ}$ C. II. 100 x KIC (Kinase Inhibitor Cocktail) in water as solvent, contained: $0.5 \mathrm{M}$ sodium fluoride $(\mathrm{NaF})$; and $0.1 \mathrm{M}$ sodium orthovanadate. The stock was aliquoted in $60 \mu \mathrm{L}$ aliquots and kept at $-20^{\circ} \mathrm{C}$. III. $40 \times$ DTT (0.1 M DTT solution is used to reduce disulphide bridges in proteins. The stock was aliquoted in $100 \mu \mathrm{L}$ aliquots and kept at $-20^{\circ} \mathrm{C}$.

\section{Determination of protein yields and cFOS / TGF- $\beta 1$ protein levels}

Protein determination of nuclear and cytosolic protein yields (presented in Table 2) was performed in microplates by a micro Lowry assay with the absorbance read at $650 \mathrm{~nm}$ (Bio Tek Instruments, Inc, Winooski, Vermont, USA). Final concentration of total proteins for both cytoplasmic and nuclear ALN tissue extracts covered the range from 3.2-9.9 mg/mL. However, the optimal total protein concentration of $2 \mathrm{mg} / \mathrm{mL}$ for TGF- $\beta 1$ and $3 \mathrm{mg} / \mathrm{mL}$ for cFOS was used for comparative analysis within the single plate/assay (Figure 3). The level of cFOS protein was determined, as described before (19) by the Transcription Factor Assay Colorimetric kit according to the manufacturer's instructions (Chemicon International, Inc. USA). The results are presented as percentage of the absorbance at $450 \mathrm{~nm}$ compared to simultaneously analyzed cFOS positive control (4 hr. time point of serum treated HeLa nuclear extracts) considered as $100 \%$. The TGF $\beta 1$ protein concentration was determined as described before (18). The immunoreactive TGF- $\beta 1$, obtained by acid-activation of latent TGF- $\beta 1$, was analyzed by the Quantikine TGF- $\beta 1$ ELISA kit according to the manufacturer's protocol for the cell culture/Urine with RD121 diluting agent (dilution factor: 14-24) (R\&D Systems Inc. Minneapolis, MN, USA). Taken together, ELISA spectrophotometric analysis for the measurements of cFOS and TGF- $\beta 1$, with the absorbances at $450 \mathrm{~nm}$ and $650 \mathrm{~nm}$, was performed on the Microplate ELISA reader Wallac 1420 (PerkinElmer, Inc, Waltham, Massachusetts, USA). The cFOS / TGF- $\beta 1$ protein levels are presented in Table 2 and Figure 3.

\section{Statistics}

For statistical analysis, the StatSoft (Hamburg, Germany) statistical package was used. All experimental points in Figure 2 and Figures 4B \& 4C were performed in duplicates. In HeLa cell measurements (Figure 1), the average variation within duplicates, for both cFOS and TGF $\beta 1$ values, was around $20 \%$, For ALN tissue extract measurements (Figures 4B \& 4C), the nonparametric Mann-Whitney $U$ test was performed to compare the relationship between the subgroup distributions of individual cFOS and TGF $\beta 1$ points in control versus metastatic nuclear and cytosolic ALN tissue extracts. Group values are expressed as the Mean values. The level of significance for all statistical tests was set at $p<0.05$. Reproducibility of the assays was determined by the Coefficient of Variation (CV) exhibiting the value range from $17.8-70.21$ $\%$. For details see the legends to Figures $4 B$ \& $4 C$.

\section{Abbreviations}

BC: Breast Cancer; ALN: Axillary Lymph Nodes; mALN: Metastatic Axillary Lymph Nodes; nALN: Normal Axillary Lymph Nodes; FNCS: Fractionated Nodal Cell Suspension; TGF $\beta 1$ : Transforming Growth Factor 
$\beta 1 ;$ H\&E staining: Haematoxylin and Eosin staining; IHC: Immunohistochemistry; TNBC: Triple Negative Breast Cancer; FCS/serum: Fetal Calf Serum; PKIC: Protein Kinase Inhibitor Cocktail.

\section{Declarations}

\section{Ethics Approval and Consent to Participate}

Surgical sample collection has been approved by the Independent Ethical committees of both the Institute of Oncology and Radiology of Serbia, and Oncology Institute of Vojvodina, Sremska Kamenica, Serbia. Before sample collection, all patients have signed an informed consent to authorize all the procedures.

\section{Consent for Publication}

Not applicable

\section{Availability of Data and Materials}

Not applicable

\section{Competing Interests}

The authors declare that the research was conducted in the absence of any commercial or financial relationships that could be construed as a potential conflict of interest.

\section{Funding}

Financial support for this work, under Research Theme "Molecular alterations as prognostic and predictive markers in human malignant tumors" - 0802103 (VM, Principal Investigator), was provided by the Ministry of Education, Science and Technological Development, Republic of Serbia (Registration number: 451-03-9/2021-14/200017). The authors have no other relevant affiiliations or financial involvement with any organization or entity with a financial interest in, or financial conflict with, the subject matter or materials discussed in the manuscript, apart from those disclosed.

No writing assistance was utilized in the production of this manuscript.

\section{Authors contributions}

ZM and BS selected, processed and performed the histological examination of surgical ALN tissue. VI and NDT developed and processed FNCS specimens including subsequent ELISA determinations. VM performed HeLa cell standardization experiments and analyzed all the data. MD performed the statistics and wrote the first draft of the manuscript. All authors participated in the final draft writing, read and approved the final manuscript.

\section{Acknowledgements}


The authors wish to thank Mr. Branislav Djurasevic for skillful literature search.

\section{Authors' information}

\section{Affiliations}

${ }^{1}$ University of Belgrade, Institute of Nuclear Sciences "Vinča", Department for Radiobiology and Molecular Genetics, Belgrade, Serbia: Vesna Ivanović, Nasta Dedović-Tanić, Miroslav Demajo, and Vesna Mandušić;

${ }^{2}$ Institute of Oncology and Radiology of Serbia, Belgrade, Serbia: Zorka Milovanović;

${ }^{3}$ Oncology Institute of Vojvodina, Sremska Kamenica, Serbia: Bratislav Stojiljković.

\section{References}

1. Bray F, Ferlay J, Soerjomataram I, Siegel RL, Torre LA, Jemal A. Global Cancer statistics 2018: GLOBOCAN estimates of incidence and mortality worldwide for 36 cancers in 185 countries. CA Cancer J Clin 2018; 68: 394-424. 7

2. Aleskandaranya MA, Vandenbergheb ME, Marchiòc C, Ellia IO, Sapino A, Rakha EA.

3. Tumour Heterogeneity of Breast Cancer: From Morphology to Personalised Medicine. Pathobiology 2018; 85: 23-34.

4. Ellsworth RE, Blackburn HL, Shriver CD, Soon.Shiong P, Ellsworth DL. Molecular heterogeneity in breast cancer: State of the science and implications for patient care. Seminars in Cell \& Developmental Biology 2017; 63: 65-72.

5. Sachs N, de Ligt J, Kopper O, Gogola E, Bounova G, Weeber F, et al. A Living Biobank

6. of Breast Cancer Organoids Captures Disease Heterogeneity. Cell 2018; 172: 373-86.

7. Lorusso G, Ruegg C New insights into the mechanisms of organ-specific breast cancer metastasis. Semin Cancer Biol 2012; 22: 226-33.

8. Tawfik K, Kimler BF, Davis MK, Fan F, Tawfik O. Ki-67 expression in axillary lymph node metastases in breast cancer is prognostically significant. Hum Pathol 2013; 44: 39-46.

9. Ivanović V, Dedović-Tanić N, Milovanović Z, Lukić S, Nikolić S, Baltić V, et al. Quantification of transforming growth factor beta 1 levels in metastatic axillary lymph node tissue extracts from breast cancer patients: a new specimen source. Anal Quant Cytol Histol. 2009; 31: 288-95.

10. Ivanović V, Dedović-Tanić N, Milovanović Z, Lukić S, Nikolić S, Baltić V, et al. Case with triple negative breast cancer shows overexpression of both cFOS and TGF- $\beta 1$ in node-positive tissue extracts. Personalized Medicine 2016; 13: 523-30.

11. Prusty BK, Das BC. Constitutive activation of transcription factor AP-1 in cervical cancer and suppression of human papillomavirus (HPV) transcription and AP-1 activity in HeLa cells by curcumin. Int J Cancer 2005; 113: 951-60. 
12. Romain S, Formento JL, Guirou O, Francoual M, Milan G, Marti M. Determination of Oestrogen Receptors by Enzyme Immunoassay. Technical Differences Between Laboratories and Their Consequences. Eur J Cancer 1994; 30: 740-6.

13. Ferrero J-M, Ramaioli A, Formento J-.L, Francoual M, Etienne M-C, Peyrottes I, et al. p53 determination alongside classical prognostic factors in node-negative breast cancer: An evaluation at more than 10-year follow-up. Ann Oncol 2000; 11: 393-7.

14. Blackburn HL, Ellsworth DL, Shriver CD, Ellsworth RE. Breast Cancer Metastasis to Axillary Lymph Nodes: Are Changes to the Lymph Node "Soil” Localized or Systemic? Breast Cancer: Basic and Clinical Research 2017; 11: 1-5.

15. Sun X, Kaufman PD. Ki-67: more than a proliferation marker. Chromosoma 2018;

16. 127.: 175-86.

17. Nasser IA, Lee AKCS, Bosari S, Saganich RS, Hartley G, Silverman ML. Occult axillary lymph node metastases in "node-negative" breast carcinoma. Hum Pathol 1993; 24: 950-7.

18. Ulmer A, Fiher JR, Schanz S, Sotlar K, BreuningernH, Dietz K. et al. Detection of Melanoma Cells Displaying Multiple Genomic Changes in Histopathologically Negative Sentinel Lymph Nodes. Clin Cancer Res 2005;11: 5425-32.

19. Weidele K, Stojanović N, Feliciello G, Markiewicz A, Scheitler S, Alberter B, et al. Microfluidic enrichment, isolation and characterization of disseminated melanoma cells from lymph node samples. Int. J. Cancer 2019; 145: 232-41.

20. Gilbert-Ramos A, Lopez C, Bosch R, Fontoura L, Bueno G, Garcia-Rojo M, et al. Immune response profile of primary tumour, sentinel and non-sentinel axillary lymph nodes related to metastasis in breast cancer: an immunohistochemical point of view. Histochemistry and Cell Biology 2019; 152: 177-93.

21. Cote RJ, Peterson HF, Chaiwun B, Gelber RD, Goldhirsch A, Castiglione-Gertsch M, et al. Role of immunohistochemical detection of lymph-node metastases in management of breast cancer. Lancet 1999; 354: 896-900.

22. Edwards $M$, Twin J, Wilkinson S. New technique to assess the axilla for breast cancer metastases using cell separation technology. ANZ J Surg 2002; 72: 655-9.

23. Greene FL, Page DL, Fleming ID. Cancer staging manual. 6th ed. New York: Springer: 2002; $221-40$.

24. Schulte EK. Standardization of biological dyes and stains: pitfalls and possibilities. Histochemistry 1991; 95: 319-28.

25. 22.. Advantages and disadvantages of immunohistochemistry. Available at: https://www.dermnetnz.org/topics/immunohistochemistry-stains/. Accessed: 09.05. 2021.

26. 23.. Bakaeean B, Gholamin M, Tabatabaee Yazdi S A, Forghani M N. Novel Biomarkers Aim at Detecting Metastatic Sentinel Lymph Nodes in Breast Cancer. Iran Biomed J. 2020; 24: $183-91$.

27. DeRose YS, Gligorich KM, Wang G, Georgelas A, Bowman P, Courdy SJ, et al. Patient derived models of human breast cancer: protocols for in vitro and in vivo applications in tumor biology and 
translational medicine. Curr Protoc Pharmacol 2013; 14.23: 1-43.

28. Mazzucchelli S, Piccotti F, Allevi R, Truffi M, Sorrentino L, Russo L, et al. Establishment and Morphological Characterization of Patient-Derived Organoids from Breast Cancer. Biol Proced Online 21, Article number:12, 2019 Available at: https://doi.org/10.1186/s12575-019-0099-8 pdf. Accessed: 12 June 2021.

29. Clevers H, Tuverson DA. Organoid Model for Cancer Research. Ann. Rev Cancer Biol 2019; 3: $223-34$. 30. Monsalve-Lancheros A, Iba' ñez-Pinilla M, Ramı́rez-Clavijo S. 2018 Detection of mammagloblin by RT-PCR as a biomarker for lymph node metastasis in breast cancer patients: A systematic review and meta-analysis.IPLOS ONE |2019, May 23. Available at:

https://doi.org/10.1371/journal.pone.0216989. pdf. Accessed: June 23, 2021.

31. Joksić G, Filipović-Tričković J, Mičić M, Joksić I, Valenta Šobot A, Demajo M. Optimization of the method for isolation of epithelial cells from the non-glandular part of the rat stomach for flow cytometry.Vet. arhiv 2020; 90: 517-25.

32. Raol HA, Jeune B, Moskovic A, Bathum L, Wang E. Optimized Lymphocyte Protein Extraction Performed Simultaneously with DNA and RNA Isolation: Application to the Study of Factors Affecting DNA, RNA, and Protein Recovery from Lymphocytes of the Oldest Individuals. Analytical Biochemistry 1999; 275: 192-201.

\section{Figures}

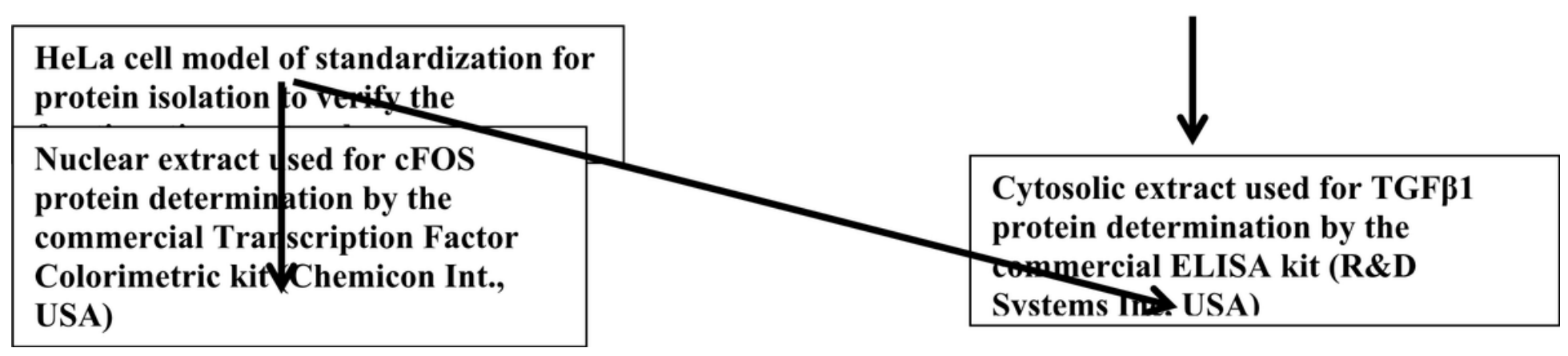

Figure 1

Workflow of the experimental design of the present study to establish and fractionate Metastatic Axillary Nodal Cell Suspension, the specimen termed Fractionated Nodal Cell Suspension (FNCS) to enable determination of protein expression level of nuclear cFOS and cytosolic TGF $\beta 1$. 


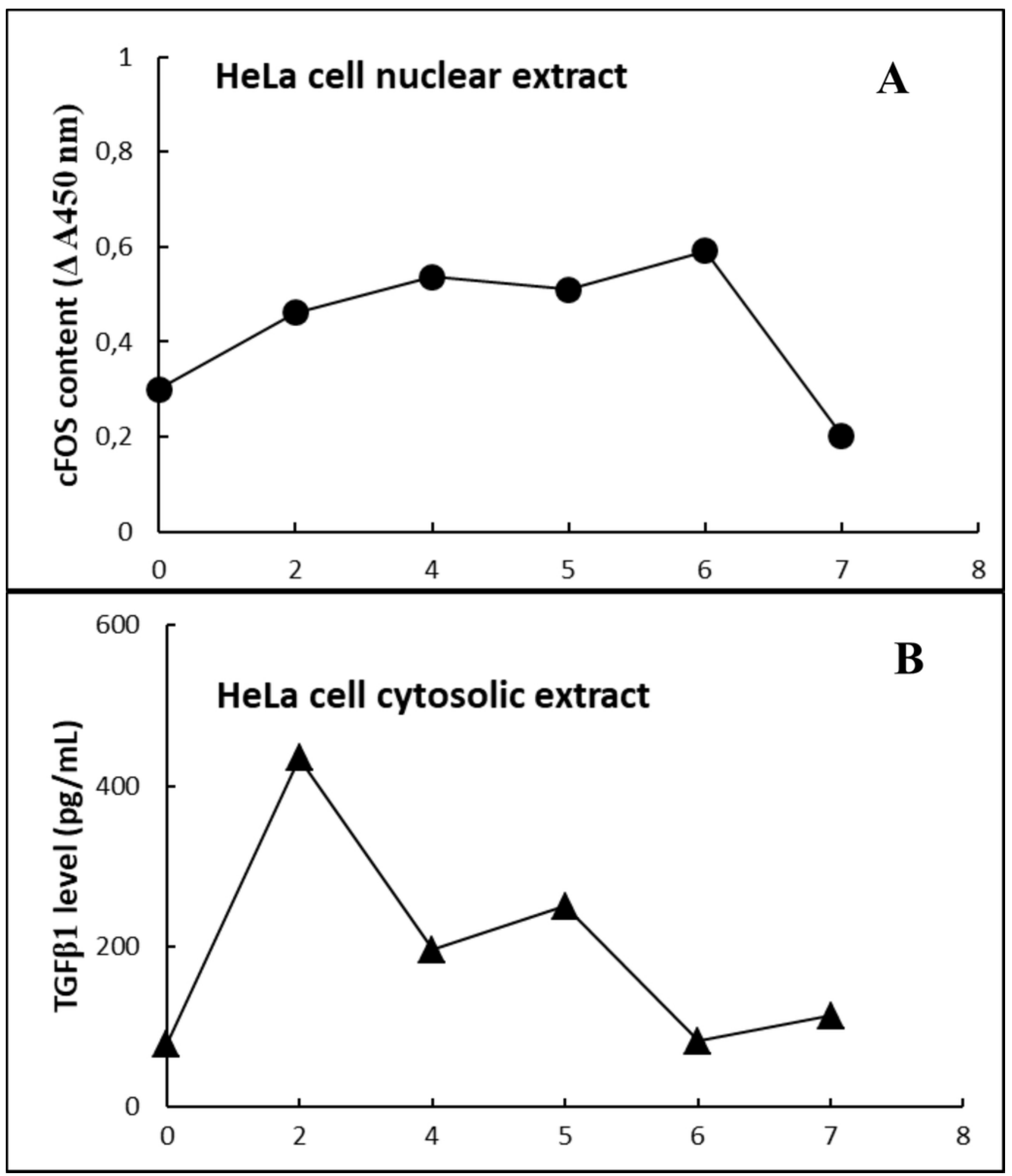

Figure 2

HeLa cell standardization presented by time curves after serum treatment for: A. nuclear cFOS protein, presented by black circles ( $(\mathbf{)})$, and B. cytosolic TGF $\beta 1$ protein, presented by black triangles $(\boldsymbol{\Lambda})$. 

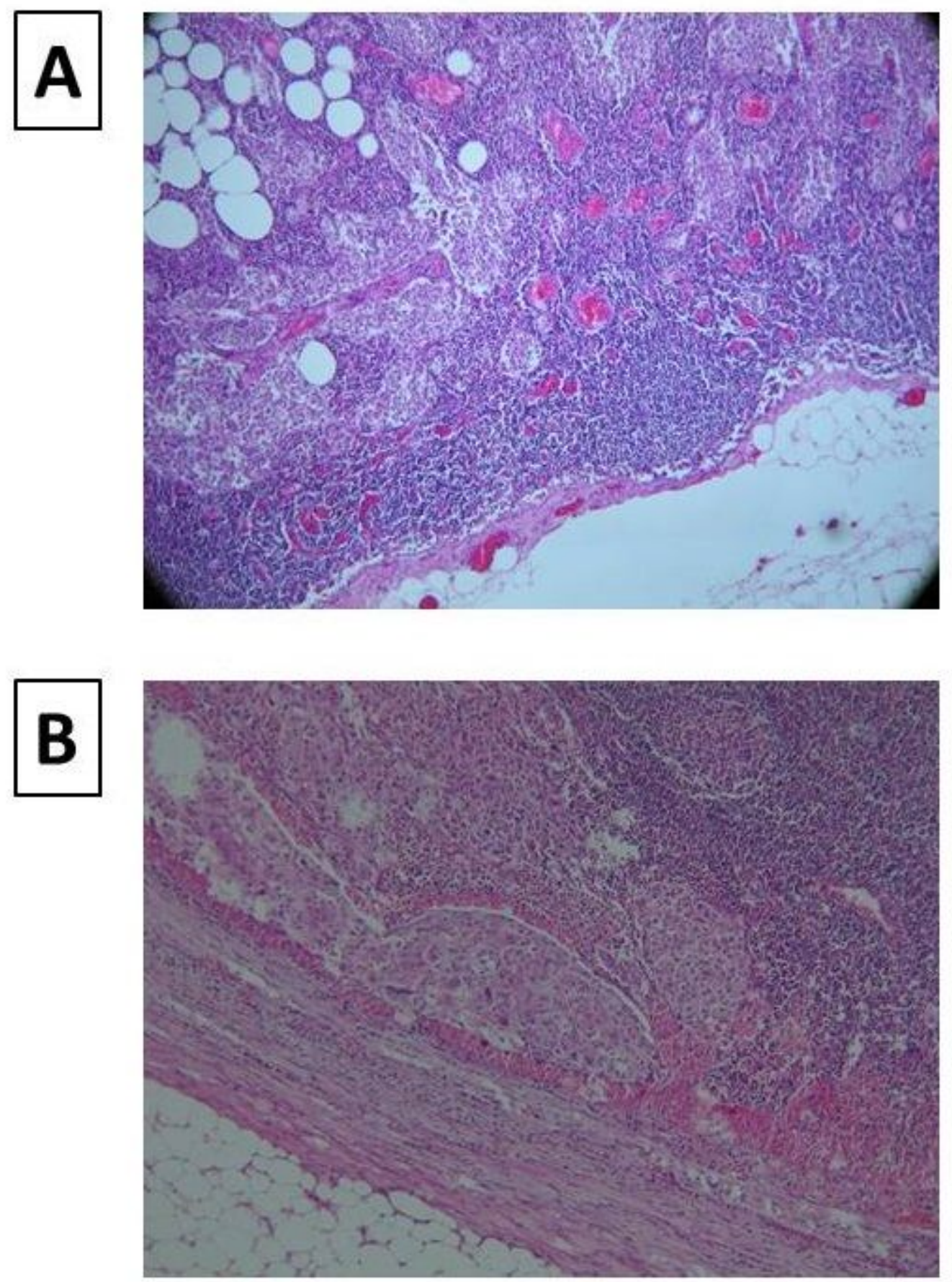

\section{Figure 3}

Comparative images of H\&E stained morphology for axillary lymph nodes of patient \#1 in Table 1: A. nALN e.i. normal ALN tissue as control, without metastatic deposits and B. Autologous metastatic ALN with near total replacement of normal lymph nodal tissue by nodules of metastasis (black dots) . 

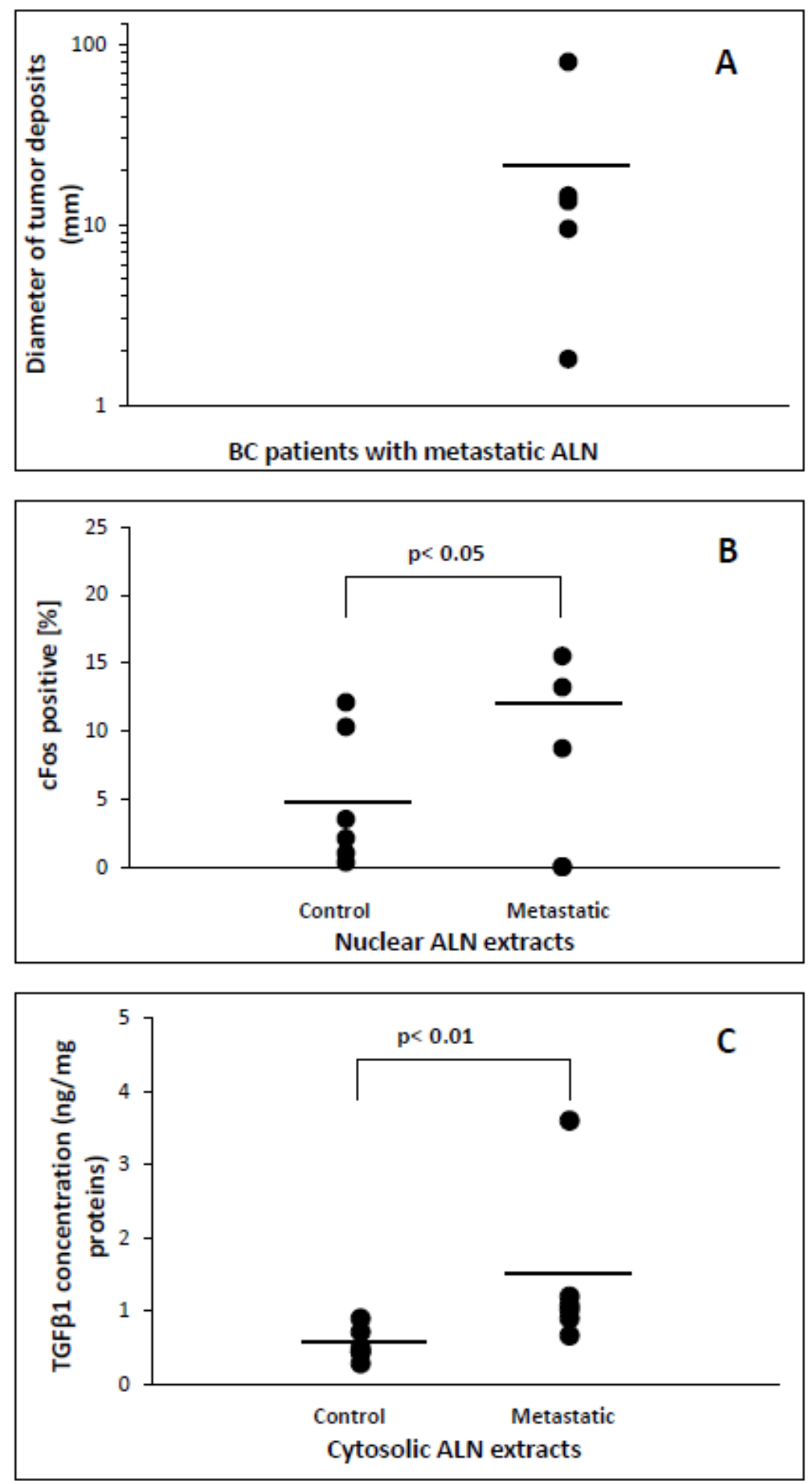

\section{Figure 4}

Comparative scatter diagrams of ALN biomarkers of BC patients described in Tables 1 \& 2. : A. diameter of tumor deposits of metastatic ALN; horizontal bar represent mean value; B. Protein level of nuclear cFOS obtained from FNCS-derived extracts of nonmalignant ALN tissue as a control versus that of the autologous metastatic ALN tissue; horizontal bars represent mean values; $p$, level of significance (Man Witney Test for nALN versus mALN p< 0.05; Control: Mean $4.89 \pm$ SEM 1.88; Metastatic: Mean $12.47 \pm$ 
SEM 1.63). C. Protein level of cytosolic TGF $\beta 1$ in FNCS-derived extracts of nomal ALN tissue as a control versus that of the autologous metastatic ALN tissue; horizontal bars represent mean values; $p$, level of significance (Man Witney Test for nALN versus mALN p< 0.01; Control: Mean $0.55 \pm$ SEM 0.08; Metastatic: Mean $1.41 \pm$ SEM 0.40 ).

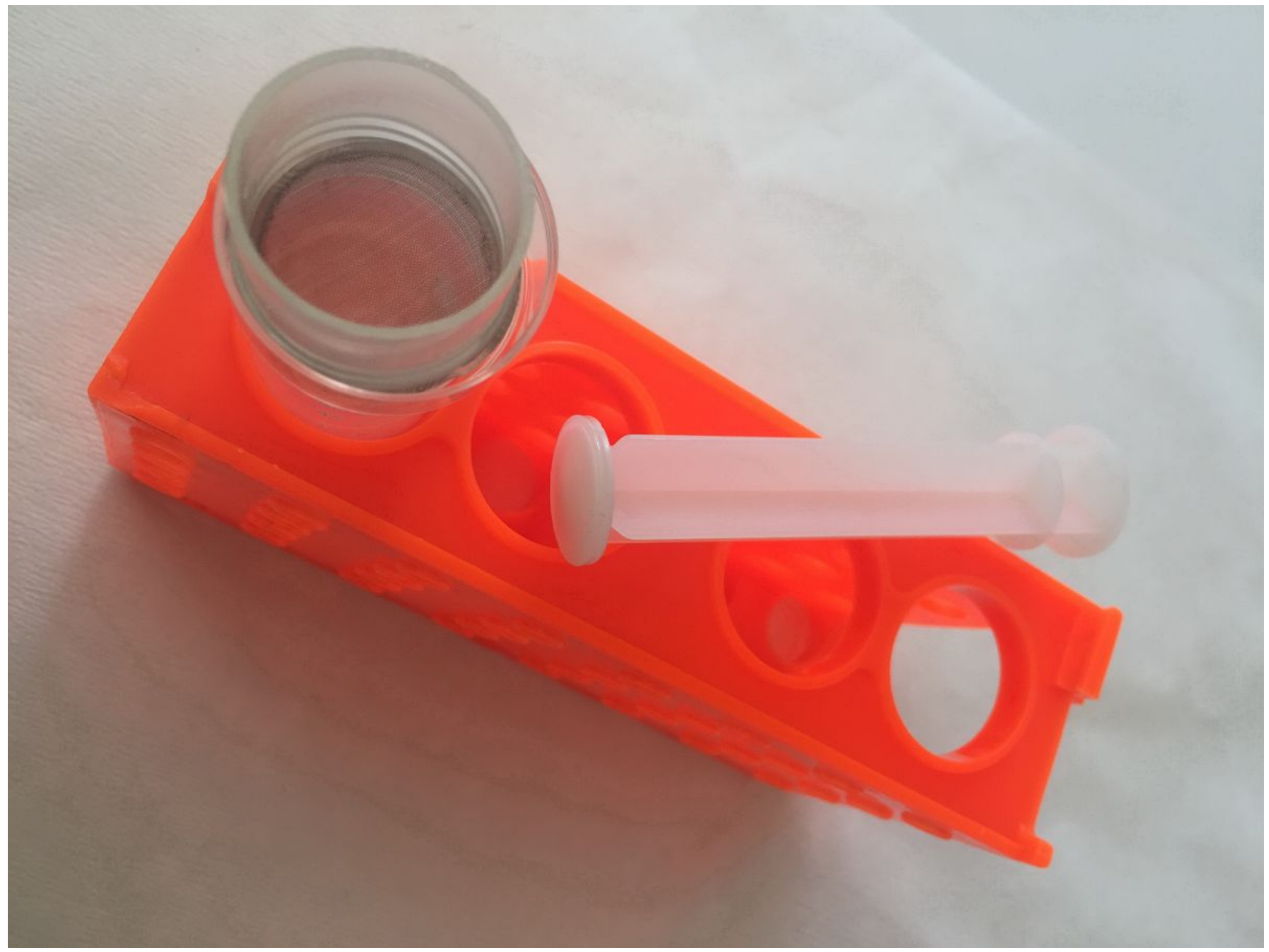

\section{Figure 5}

Image of the sieving device ( $100 \mu \mathrm{m}$ cell strainer) for pulverization and filtration of ALN tissue to obtain cell suspension free from fat and connective tissue. 